\title{
La paideia como estructura fundamental del quehacer teológico en Gregorio de Nisa
}

\author{
ORLANDO SOLANO PINZÓN \\ Pontificia Universidad Javeriana (Colombia) \\ o.solano@javeriana.edu.co
}

\begin{abstract}
Resumen
El presente artículo busca dar razón de la categoría paideia como estructura fundamental del quehacer teológico de Gregorio de Nisa. En función de este propósito se hace un acercamiento a la noción de paideia propia de los griegos y, posteriormente se señala la manera como el Niseno apropió dicha categoría configurando la paideia cristiana, apelando a ejemplos de su obra De Vita Moysis.
\end{abstract}

Palabras clave: Patrística, paideia, Gregorio de Nisa, inculturación, teología.

\section{The paideia as fundamental structure of the theological work of Gregory of Nyssa}

\begin{abstract}
This article seeks to give reason for the category paideia as a fundamental structure of the theological enterprise of Gregory of Nyssa. According to this purpose is made an approach to the concept of paideia own of the Greeks and subsequently notes how the bishop of Nyssa appropriated that category by configuring the Christian paideia, appealing to examples of his work De Vita Moysis.
\end{abstract}

Key words: Patristic, paideia, Gregory of Nyssa, inculturation, theology.

Licenciado en Filosofía de la Universidad Santo Tomás, sede Bogotá; Profesional, Licenciado, Magister y Doctor en Teología de la Pontificia Universidad Javeriana, sede Bogotá. Docente de tiempo completo de la Facultad de Teología de la Pontificia Universidad Javeriana. Miembro del grupo de investigación Academia. Artículos publicados recientemente: "La alienación de la libertad en la era postsecular" (2013); "El despertar de la espiritualidad de la liberación: evolución de sus expresiones" (2013); y "La hermenéutica ricoeuriana en el diálogo entre las ciencias patrísticas" (2014). 


\section{Introducción}

El presente escrito corresponde al texto ajustado de la sustentación de la tesis doctoral": "Inculturación de la teología. Aportes desde la paideia cristiana en el De Vita Moysis de Gregorio de Nisa", cuyo objetivo se orientó en función de caracterizar un marco conceptual que permita sustentar la inculturación de la teología, a partir del aporte de la tradición representada en la paideia cristiana de Gregorio de Nisa en su obra antes mencionada ${ }^{2}$.

$\mathrm{El}$ aporte fundamental que está a la base de la investigación realizada no radica en afirmar que los Padres de la Iglesia son maestros de inculturación de la teología, sino en mostrar a través de la obra de uno de ellos, la manera como dicha inculturación se concreta. En este sentido, el presente artículo busca hacer una breve caracterización del proceso de apropiación de la paideia griega realizado por Gregorio de Nisa, para lo cual, en un primer momento se hará un acercamiento a la categoría paideia, posteriormente se hará referencia a la manera como Gregorio asume dicha categoría, evocando fragmentos de la obra antes mencionada y por último cerraremos con una conclusión.

\section{Noción de paideia}

Para abordar la categoría paideia, es oportuno referir el trabajo realizado por Werner Jaeger, ya que fue el inspirador de la presente investigación, particularmente desde su obra Cristianismo primitivo y paideia griega. $\mathrm{Si}$ bien Jaeger había dedicado todo un memorable estudio a la paideia griega, al terminar dicha obra reconocía que, sin la intervención del cristianismo, al que consideraba como la última fase de la paideia griega, poco o nada habría sobrevivido de la literatura y de la cultura clásica (García Gibert, 2010).

Jaeger fue un gran conocedor de la obra de Gregorio de Nisa, debido a que dedicó parte de sus últimos años a la edición del texto griego de los escritos del Niseno necesitados de una reconstrucción científica. En este sentido, es él quien gracias al conocimiento que poseía del autor, afirma que «la estructura de la teología del Niseno está permeada por la

\footnotetext{
1 La tesis fue sustentada el 16 de septiembre de 2014 en el auditorio Mariano Troncoso de la Pontificia Universidad Javeriana.

2 La tesis buscó responder a la gran dificultad en la inculturación que vive la teología y cuya necesidad urgente de inculturación ha sido reclamada por diferentes voces en el continente, entre ellos es posible mencionar a Verteuil (1994), Susin (1995), Ramos (2001), Garrard-Burnett (2004), Estermann (2008), Escalante (2010) y Aguilar (2010).
} 
idea griega de paideia, sobre todo en su forma platónica» (Jaeger \& Frost, 1974: 136).

Más aún, para Jaeger \& Frost (1974: 121, 122):

Gregorio recurre en sus obras, una y otra vez, al concepto de educación que era, por así decirlo... el ideal a priori de toda la reflexión griega sobre este problema: el concepto de morphosis. Su constante repetición de esta imagen básica, que implica la identidad esencial de toda actividad educativa y la obra del artista creador, pintor, escultor, revela la naturaleza plástica de su concepción de la paideia griega.

Según Jaeger (2001), la cultura griega además de haber sido la primera en dejar constancia de la preocupación por la formación del hombre, se desarrolló no destruyendo sus bases previas, sino siempre transformándolas. En este sentido, el modelo que había venido empleándose hasta entonces no era arrojado como inservible, sino renovado rigiéndose por la ley de la estricta continuidad. La filosofía de Platón es ejemplo de ello al buscar reintegrar los períodos anteriores de la cultura helénica. En efecto, afirma Jaeger (2001: 374), «Platón recoge deliberada y sistemáticamente, los diversos problemas del periodo preplatónico y los lleva a un plano filosófico más elevado».

Entre estos diversos problemas se ubica el de la paideia, que aparece en el siglo $V$ en un escrito de Esquilo (Jaeger, 2001) y que fue convirtiéndose en expresión auténtica de los afanes espirituales en tiempos de Platón a quien Jaeger (2001: 375) reconoce como «el verdadero filósofo de la paideia». Dicha paideia era entendida como el despertar a un ideal consciente de educación del hombre de acuerdo con la verdadera forma humana, con su auténtico ser; y de cultura, que se había ido gestando por la mediación de la filosofía, la ciencia y, en lucha constante con ellas, el poder formal de la retórica.

Según Jaeger (2001: 12),

este ideal del hombre, mediante el cual debía ser formado el individuo, no es un esquema vacío, independiente del espacio y del tiempo. Es una forma viviente que se desarrolla en el suelo de un pueblo y persiste a través de los cambios históricos. Recoge y acepta todos los cambios de su destino y todas las etapas de su desarrollo histórico.

El molde de la paideia griega en su primer momento fueron los héroes de Homero, posteriormente los sofistas añadieron las artes liberales y, finalmente Platón concibió la filosofía como la paideia superior. En este sentido, es oportuno afirmar que los verdaderos representantes de la paideia griega no son los artistas mudos, es decir, escultores, pintores, 
arquitectos, sino los poetas, los músicos, los filósofos, los retóricos y los oradores.

Platón, marcado por la experiencia vivida junto a su maestro Sócrates, verá en su figura el eje de la formación del hombre griego por su propio esfuerzo. Esta idea de modelo y el ejemplo dominaba la educación aristocrática desde Homero. Según Jaeger (2001: 284), «en el ejemplo personal se muestra vivamente ante los ojos del educando la norma que debe seguir y la mirada atenta ante la encarnación de la figura ideal del hombre debe moverlo a la imitación». Este elemento personal de la imitación ( $\mu$ í $\eta \sigma \iota \varsigma$ ) es posteriormente reemplazado por la ley.

La referencia a Sócrates como modelo de paideia permite comprender mejor algunas características fundamentales que asume. Cuando él concibe su labor de persuasión a jóvenes y viejos, de no preocuparse tanto ni por su cuerpo ni por su fortuna sino por la perfección de su alma, como ordenada por Dios y, por esta razón, como un servicio rendido a Dios, nos sitúa frente a la finalidad de la misma paideia (Jaeger, 2001). Este carácter religioso de su misión se comprende desde la lógica de la cura del alma, pues el alma es para él lo que hay de divino en el hombre. Según Jaeger (2001c: 443),

El llamamiento de Sócrates al 'cuidado del alma' fue lo que realmente hizo que el espíritu griego se abriese paso hacia la nueva forma de vida. Si el concepto de la vida, del bíos, que designa la existencia humana, no como un simple proceso temporal, sino como una unidad plástica y llena de sentido, como una forma consciente de vida, ocupa en adelante una posición tan dominante en la filosofía y en la ética, ello se debe, en una parte muy considerable, a la vida real del propio Sócrates. Su vida fue un anticipo del nuevo bios, basado por entero en el valor interior del hombre.

Sócrates caracteriza más concretamente el cuidado del alma como el cuidado por el conocimiento del valor y de la verdad, frónesis y alétheia. El saber socrático o frónesis no tiene más objeto que uno: el conocimiento del bien. Allí donde la voluntad se concibe de este modo profundamente positivo y consciente de su fin, se basa siempre por naturaleza en el saber, y la consecución de este saber, cuando es posible, representa la perfección humana. Desde que Sócrates concibió esta idea, hablamos de un destino del hombre y de una meta de la vida y la conducta humanas. La meta de la vida es lo que la naturaleza quiere por su esencia y su naturaleza: el bien (Jaeger, 2001).

En efecto, esta noción de meta de la vida va a ser decisiva para la historia de la paideia, pues permite iluminar de un modo nuevo la misión de toda educación que ya no consistirá más en el desarrollo de ciertas 
capacidades ni en la trasmisión de ciertos conocimientos, sino en poner al hombre en condiciones de alcanzar la verdadera meta de su vida. Esta aspiración sólo puede alcanzar su fin a lo largo de toda la vida del hombre. Según Jaeger (2001c:450),

esto hace que cambie el concepto de la esencia de la paideia. La cultura en sentido socrático se convierte en la aspiración a una ordenación filosófica consciente de la vida que se propone como meta cumplir el destino espiritual y moral del hombre. El hombre, así concebido, ha nacido para la paideia. Ésta es su único patrimonio verdadero.

De acuerdo con lo anterior, la suma y compendio de todo lo que posee el hombre es, desde la perspectiva socrática, la paideia: su forma interior de vida, su existencia espiritual, su cultura. Además, en esta comprensión de la paideia se conjugan y se integran de una manera excelente el sentido especulativo de la vida teórica y el sentido práctico de la vida virtuosa. Paideia es a la vez el ideal a que ha de tenderse y el proceso por el cual se va alcanzando progresivamente dicho ideal, marcado por la experiencia de la kaloka-gathía, es decir de lo bello y de lo bueno. Constituye la interiorización jerárquicamente estructurada de los valores y la conformación del mundo con calidad humana. La paideia es al mismo tiempo un resultado: el hombre mismo que alcanza la estatura perfecta y los elementos modeladores con los que tal logro es obtenido.

En la comprensión de paideia en Platón, el estado es necesario para que pueda existir una educación. Necesario no sólo como autoridad legislativa, sino también como el medio ambiente, como la atmósfera que respira el individuo. Según Jaeger (2001c:623),

no basta con que el alimento espiritual de la cultura musical sea puro; las obras de todas las profesiones, todo lo que tiene forma debe reflejar el mismo espíritu de una actitud noble y unirse en la aspiración hacia una perfección suma y hacia el decoro y la dignidad. Es necesario que todo el mundo, desde su más tierna infancia, respire en este ambiente algo así como el aire de una comarca sana.

\section{Uso de la noción de paideia por Gregorio de Nisa}

La caracterización de la noción de paideia elaborada en el apartado anterior, que se forjó en el siglo IV a.C. va a mantenerse en los siglos venideros y con ella se encontrarán los autores cristianos de los primeros siglos en su diálogo con la cultura griega. Según Jaeger \& Frost (1974), la 
rápida asimilación del ambiente griego que efectúan las primeras generaciones cristianas obedece a que

el cristianismo era un movimiento judío y los judíos estaban ya helenizados en tiempos de San Pablo, no sólo los judíos de la diáspora sino también, en gran medida, los de Palestina misma; y a que fuera precisamente esta porción helenizada del pueblo judío hacia la que se volvieran en primer lugar los misioneros cristianos (Jaeger \& Frost, 1974: 14-15).

Particularmente serán los padres griegos, entre ellos, Justino, Clemente, Orígenes y los capadocios, en su mayoría pertenecientes a la escuela de Alejandría, quienes contribuirán a un renacimiento de la cultura griega. En palabras de Jaeger \& Frost (1974: 61-62),

los ideales culturales griegos y la fe cristiana se mezclaron, por muy ansiosos que estemos de conservar inmaculados unos y otra. Había, en ambas partes, un intenso deseo de penetración mutua, sin tener en cuenta, por ahora, lo reacios a asimilarse que eran estos dos lenguajes, cada uno de los cuales tenía sus diferentes maneras de sentir y de expresarse a sí mismo en forma metafórica.

Dentro de las características que hacen parte de la escuela de Alejandría que va a tener una incidencia en Gregorio de Nisa, se encuentra la importancia que va a adquirir en ella la filosofía (y la cultura pagana) en su relación con la teología. No es que los teólogos cristianos anteriores no utilizaran conceptos o referencias filosóficas, pero no consideraban la filosofía como una etapa previa o preparación para el auténtico conocimiento de Dios. Esta importancia se va a reflejar en el uso amplio que hacen de citas clásicas, la utilización del proceso formativo habitual en las escuelas paganas (que es explícito primero en Clemente de Alejandría a través de sus obras: Protréptico, Pedagogo y Didáscalos al cual nominó como Stromata $=$ Tapices; y posteriormente en Orígenes), el empleo de conceptos originarios de la filosofía de su tiempo para explicar realidades procedentes de la revelación e incluso la utilización de los recursos filológicos, que habían sido adoptados por los comentaristas de Homero y Hesíodo para explicar la Sagrada Escritura (Orlandis, 1999).

González (2002-2003) al referirse al uso de la filosofía por parte de los Padres Griegos señala que ellos tuvieron como modelo a los judíos helenizados, quienes establecieron un primer puente de diálogo y encuentro entre dos culturas diferentes. Concretamente Filón de Alejandría haciendo uso de la interpretación alegórica estableció comparaciones 
entre ciertos pasajes bíblicos con historias míticas griegas y reprochó a quienes se empecinaban en ver simples mitos en los textos sagrados.

Para Jaeger \& Frost (1974: 93), la relación de la religión cristiana con la herencia cultural griega

hizo que la gente se percatara de que ambas tradiciones tenían mucho en común, si se las consideraba desde un punto de vista superior, el de la idea griega de paideia o educación, que ofrecía un denominador común único para ambas.

Esta importancia de la filosofía tiene una de sus expresiones más cualificadas en el concepto de paideia que para Orígenes se convirtió en la clave de la verdadera relación entre la religión cristiana y la cultura griega. El cristianismo Alejandrino va a usar esta cultura como base de su reflexión, pero transformándola ahora en paideia cristiana, cuya fuente será el Logos divino, del que tanto griegos como bárbaros van a ser instrumentos; de esta manera se negará todo valor a la religión pagana, aunque se admita la importancia de su cultura (Uribarri, 2007).

Concretamente, con Gregorio de Nisa, el cristianismo alcanzó un punto en el que saca sus propias conclusiones de la gran experiencia griega expresada en la idea de paideia y le es posible comprender aspectos centrales del verdadero significado de la misma, entendida como perfección del alma que no sólo se circunscribe a esta vida, sino que continuará por toda la eternidad. Para el Niseno, la educación es un proceso formativo de la personalidad concebida como morphosis, cuyo ideal pedagógico cristiano reposa sobre la paideia en el sentido de la naturaleza plástica del alma, en donde se esculpen en ella «formas» que la embellecen y desarrollan su personalidad (Jaeger \& Frost (1974).

Jaeger \& Frost (1974: 125-126) expresan este proceso de apropiación de la paideia por parte de Gregorio en los siguientes términos:

Si la paideia era la voluntad de Dios y si el cristianismo es para el cristiano lo que la filosofía para el filósofo, según Platón —asimilación de Dios-, el verdadero cumplimiento del ideal de vida cristiano es el esfuerzo continuo por llegar a ese fin y por acercarse a la perfección en la medida en que esto es posible al hombre. Así como toda la vida del filósofo griego era un proceso de paideia a través de la ascesis filosófica, para el Niseno el cristianismo no es un mero conjunto de dogmas, sino la vida perfecta basada en la theoria o la contemplación de Dios y en una unión cada vez más perfecta con él. Es la deificatio y el camino a ella es la paideia.

Dicha paideia evoca la metáfora del crecimiento gradual del ser espiritual humano y su analogía con la naturaleza física del hombre; sin em- 
bargo, la nutrición del alma es diferente a la del cuerpo al requerir un cuidado constante, que para Gregorio ofrece la Iglesia a través de los sacramentos (Jaeger \& Frost, 1974).

En este orden de ideas, cuando el obispo de Nisa habla de paideia, se refiere sobre todo a lo que distingue su forma cristiana de la griega, entendida como perfección del alma que no sólo se circunscribe a esta vida, sino que se prolonga por toda la eternidad. Por esta razón, frente al corpus entero de la literatura griega que era concebida como paideia, en la medida que contenía las reglas cualificadas de la vida humana, para Gregorio su correlativo cristiano corresponde a la Biblia y su molde es Cristo. En ello se resumen los ideales más altos de la vida humana y Cristo es la imagen ideal o el gran paradigma del hombre (Jaeger \& Frost, 1974).

En este sentido, la paideia del cristiano es la imitatio Christi, cuya morphosis se plasma cuando Cristo toma forma en él. En este proceso formativo, el Espíritu Santo se convierte en una fuerza educadora que habla a través de los seres humanos y los conduce a la adquisición de las virtudes. En este caso, el perfeccionamiento humano es posible por la ayuda y la gracia divina, concebida como la cooperación del Espíritu Santo con el esfuerzo humano. Dicha cooperación se entiende debido a que el Niseno no le menoscaba potencialidad a lo humano para su desarrollo espiritual, intelectual y moral; incluso considera que el auxilio divino se incrementa en proporción al esfuerzo humano (Jaeger \& Frost, 1974).

Ahora bien, según Jaeger \& Frost (1974: 125-126), para Gregorio el cristianismo no es únicamente un conjunto de dogmas, sino esencialmente una «contemplación de Dios y una unión cada vez más perfecta con Él. Es la deificatio y el camino a ella es la paideia, la Anábasis divina». Además, considera que la religión de Cristo es una forma de vida, a la que denomina «vida filosófica», entendida de acuerdo con un género de vida ascética que seguía ideales monásticos.

En este orden de ideas, la historia personal de Cristo es paideia definitiva para el hombre, que en la humanidad y en el corazón del Hijo ha accedido a la intimidad del Padre, pero esto es posible sólo en la mímesis, gracias a la cual la oikonomía de la libertad humana hace propia la oikonomía divina. Y la auténtica imitación se da sólo en la identificación mística y sacramental con Cristo; esta idea de afirmación mística y sacramental se encuentra a la base de la interpretación alegórica que Gregorio desarrolla en la segunda parte del De Vita Moysis (Daniélou, 1941: 32-135).

Este acercamiento a la categoría paideia nos permite evidenciar el vínculo que tiene la teología del Niseno con la idea griega de paideia, sobre todo en su forma platónica en la cual la paideia deriva del nous divino. Para el Niseno, la educación filosófica griega ofrecía una analogía com- 
pleta con la teología cristiana tal como él la entendía; por ello, según Jaeger \& Frost (1974), usa las formas griegas como modelo estructural de una cultura completamente desarrollada, y por medio de la comparación crea respecto a cada una de ellas una variante cristiana conformada en el molde clásico pero, a la vez, muy claramente diferente a él.

En esta misma línea se ubica Ferrer (2006) en cuanto plantea que Gregorio hizo uso del lenguaje propio de la filosofía, pero «su pensamiento cristiano desbordó esas formas concretas ya existentes, determinando modos propios de expresión, que contribuyeron a dar forma a una profunda experiencia espiritual». Daniélou (1976: 28-39) también afirma que

Gregorio no ha permitido ninguna discrepancia entre su teología y su trasfondo, la teología metafísica de los platónicos. Lo que estaba en contradicción lo ha dejado de lado, casi siempre con cuidadosa fundamentación.

Lo anterior permite referir, por un lado, que el elemento diferenciador es siempre la fe cristiana que constituye el alma de su impulso intelectual (Ruiz, 2007) y, por otro lado, que tenía un conocimiento amplio de la gran tradición filosófica griega y sus ideales culturales, que le permitían asumirla, desde la fe, como un nuevo punto de partida hacia una educación cristiana.

En efecto, la formación del hombre cristiano, su morphosis, es el resultado del incesante estudio de la Biblia y de la adecuación a la forma o el molde que es Cristo. Esta comprensión de la Biblia como paideia permite comprender mejor la manera como el obispo de Nisa hace uso de la misma, siempre como autoridad suprema (Balderas, 2007; Trevijano, 1994). Al respecto, en lugar de decir, «el profeta dice» o «Cristo dice», que son formas comunes de expresión, escribe innumerables veces «el profeta Isaías nos instruye, nos enseña' o 'el apóstol nos instruye, nos enseña».

Según Jaeger \& Frost (1974:131-132), desde la comprensión de la Escritura como paideia,

la figura de Moisés aparece como el modelo perfecto del santo y del místico, el prototipo de lo que el Niseno llama la vida filosófica o contemplativa, el hombre cuya vida fue vivida en una incesante comunión con Dios, el hombre que ascendió a la cima de su Sinaí espiritual a fin de ver a Dios en la oscuridad de una nube.

Lo anterior se hace más evidente en cuanto Gregorio concibe la Escritura como inspirada por el Espíritu Santo y, por esta razón, como una 
unidad, como un todo que integra diferentes autores quienes reciben la autoridad pedagógica del mismo Espíritu. Éste constituye la fuerza educadora divina perennemente vigente en el mundo y su forma de hablar a la humanidad a través de las Escrituras es la de un sabio educador que jamás olvida los estrechos límites de capacidad de sus discípulos. Por este motivo, el lenguaje antropomórfico que se usa en las Escrituras en relación con las cosas divinas, sirve sólo como punto de partida para el proceso de una comprensión más profunda.

En el ejercicio de correlación que realiza Gregorio entre la paideia griega y su consolidación de la paideia cristiana, concibe que la paideia clásica está siendo superada, pues Cristo desborda los limitados esquemas de la cultura griega y se constituye en el centro de una cultura nueva. De esta manera, la paideia antigua se convierte en su instrumento, en propaideia, que es la manera como el Niseno la asume. Más aún, según Según Jaeger \& Frost (1974:93-94),

La fusión de la religión cristiana con la herencia cultural griega hizo que la gente se percatara de que ambas tradiciones tenían mucho en común, si se las consideraba desde un punto de vista superior, el de la idea griega de paideia o educación que ofrecía un denominador común único para ambas... El cristianismo lejos de diluirse se afirmó y consolidó su supremacía; usando esta cultura internacional como base, se convirtió ahora en la nueva paideia cuya fuente era el logos divino, la Palabra que había creado al mundo. Tanto los griegos como los bárbaros eran sus instrumentos.

En términos generales es posible afirmar que la estructura del teologizar del Niseno está permeada por la idea de paideia en la cual se integran, tanto el ideal a que ha de tenderse como el proceso por el cual se va alcanzando progresivamente dicho ideal. Esta correlación se hace evidente en el De vita Moysis, ya que tiene como punto central la Biblia, no como recetario para justificar opiniones personales sino como fuente del proceso de formación del hombre en función del molde que es Cristo. Particularmente, será a partir del relato bíblico de la historia de Moisés, que identificará los pasos a seguir en dicho proceso.

Ahora bien, el proceso de formación o deificación se sitúa, en la lógica del teologizar del Niseno, tanto en la mutua relación (en su recíproca distinción sin separación y unión sin confusión) que busca establecer entre historia (en este caso la historia de Moisés), oikonomia (la comprensión de la historia de Moisés dentro del plan de salvación de Dios) y teología (en la manera como dicha historia permite adentrarse en el conocimiento de Dios); como en el doble movimiento de exitus marcado por la 
caída del hombre en el pecado y de reditus comprendido como el retorno del alma a Dios, a su naturaleza original como imagen de Dios. Según Daniélou (1944: 8), la imagen de Dios para Gregorio «es la vida divina, que es un don de la gracia». En este sentido, la teología para Gregorio se entiende no como un ejercicio meramente especulativo, sino como una aventura existencial que abraza todo el espectro de la vida humana.

\section{La paideia cristiana y el De Vita Moysis}

A partir de la comprensión propia de la paideia griega, Gregorio empieza a echar mano de ideas que eran parte de la cultura como: la correlación directa que en la filosofía clásica se establecía entre Dios y el Bien al equipararlos, las partes del alma, el mito de la caverna, la cura de almas, el servicio a Dios como fin de la vida, entre otros. El Niseno hace uso de la equiparación, pero con una carga de significado diferente en los conceptos, ya que la comprensión de los mismos tendrá como referente fundamental la Escritura.

En el caso particular de la concepción de Dios, corresponde al Dios de Israel, el totalmente Otro, el Dios vivo y personal que se manifiesta en la historia, no a la idea filosófica del Uno de Plotino ni a la comprensión confusa sobre lo divino de Platón que se confunde con las creaturas. La característica fundamental de Dios para Gregorio es que Dios es infinito y por ello incomprensible e inabarcable (Daniélou, 1941: 3).

Ahora bien, al relacionar esta comprensión de Dios con el Bien cuya esencia es la Bondad, remite al texto de Filipenses 3,12-14:

Esto no quiere decir que haya alcanzado la meta ni logrado la perfección, pero sigo mi carrera con la esperanza de alcanzarla, habiendo sido yo mismo alcanzado por Cristo Jesús. Hermanos, yo no pretendo haberlo alcanzado. Digo solamente esto: olvidándome del camino recorrido, me lanzo hacia delante y corro en dirección a la meta, para alcanzar el premio del llamado celestial que Dios me ha hecho en Cristo Jesús.

Para concluir que el Bien es infinito y, por este motivo, la perfección en la virtud consiste en no tener límites, es decir, en ser infinita. En este caso, para el hombre que es finito y, por esta razón, limitado por naturaleza, la perfección consiste en no parar nunca de crecer en la virtud (Epéktasis), más aún, sólo en el firme y constante crecimiento interior puede el hombre imitar la absoluta inmutabilidad divina (Daniélou, 1941: 3-4).

Por otro lado, así como en la paideia griega había una serie de personajes a los que se consideraba como modelos, tales como Homero, Só- 
crates, Platón, entre otros, el Niseno ve en los personajes bíblicos a los modelos de la paideia Cristiana. Por este motivo, escoge a Moisés como modelo de hombre virtuoso que permite comprender en qué consiste la vida perfecta y presenta una historia de este personaje. Para tal efecto, hace uso de la exégesis literal y la aggadah judía recogiendo información de los libros del Éxodo, los Números y una vida de Moisés que había elaborado Filón de Alejandría.

La reconstrucción de la historia de Moisés en clave de vida virtuosa se convierte en la segunda parte del De vita Moysis (Daniélou, 1941: 32 135), en la base para una interpretación más profunda desde la exégesis alegórica que busca el sentido espiritual. Además, Gregorio interpreta la vida de Moisés como alegoría del itinerario del alma hacia Dios, quien es la Virtud Perfecta o el Sumo Bien. En este sentido, la dinámica de la exposición de las ideas va a consistir en mostrar comentando los sucesos de la vida de Moisés que, en el caminar hacia Dios, hacia la virtud perfecta, a una etapa sigue siempre otra, y a una ascensión sucede siempre otra. Lo anterior, permite comprender que para el Niseno la paideia cristiana es participación en la bondad de Dios, es asemejarse a Dios, que es posible para el hombre debido a que fue creado a imagen y semejanza del Creador.

Sobre la base de la exégesis alegórica, Gregorio va a darle a la paideia cristiana una fundamentación metafísica que la sustenta haciendo uso en su argumentación, tanto de la Escritura, como de ideas propias de la cultura filosófica y retórica de su momento. El esquema de base lo constituye la historia de Moisés, particularmente en las tres teofanías que recibe: la de la zarza ardiendo (Ex 3, 1-15), la del monte Sinaí al recibir la Ley (Ex 19, 16-25), y la de la hendidura de la peña (Ex 34, 6-9), buscando presentar el itinerario de Moisés como una ascensión coherente y constante hacia la total unión con Dios.

En la teofanía de la zarza ardiendo (Ex 3, 1-15) (Daniélou, 1941: $37-$ 42), Moisés experimenta el encuentro con la verdad, de forma que ella llena con sus propios destellos los ojos del alma. El Niseno subraya la unión perfecta que se da entre el ser, la verdad y el bien, aclarando que la verdad es un conocimiento firme de lo que existe verdaderamente, por esta razón, consiste en no errar en el conocimiento del ser, en este caso, de Dios, quien es el sumo Bien. En cuanto al error, lo concibe como una ilusión que se produce en el pensamiento en torno a lo que no es, como si lo que no existe tuviese consistencia. En este orden de ideas, señala que Moisés instruido por la teofanía ha comprendido que fuera de la causa suprema de todo, en la cual todo tiene consistencia, ninguna de las cosas que se captan con los sentidos y que se conocen con el pensamiento tiene consistencia en el ser. 
$\mathrm{Al}$ interior de ésta última afirmación está presente toda la fuerza del hombre de fe que ve a Dios en todas las cosas y que, al mismo tiempo, comprende que la belleza del ser estriba precisamente en que, para los ojos del alma, resulta transparencia de la belleza divina en la que todo ser encuentra su consistencia. En clave de paideia es posible afirmar que el reconocimiento que hace Moisés de Dios obedece a la experiencia de purificación, con su doble faceta de apartamiento del mal y de elección del camino recto, que es promovida por la buena educación que se constituye en la arqueta que protege en medio de las olas de la vida. Según Daniélou (1941: 33-34), Gregorio utiliza intencionadamente la imagen de la arqueta tejida con mimbres diversos para defender una educación que consta de disciplinas diversas.

Para el obispo de Nisa, la educación es de primordial importancia en todo hombre, pues el nacimiento verdaderamente humano, el que hace nacer al hombre a su verdadera humanidad, tiene lugar precisamente mediante el ejercicio de la libertad. Es a la libertad, y sólo a ella, a la que corresponde humanizar al hombre, más aún, sólo es posible vencer al enemigo del hombre mediante la libertad del hombre mismo (Daniélou, 1941: 32-33).

La siguiente teofanía que aborda el De vita Moysis tiene lugar en el monte Sinaí, en la cual el obispo de Nisa utiliza la imagen de la tiniebla que tiene una particularidad, en cuanto que al mismo tiempo es luminosa. El Éxodo describe a Moisés en el Sinaí adentrándose en la densa nube donde está Dios (Ex 20, 21) (Daniélou, 1941: 77-79).

Si bien la primera teofanía fue a través de la luminosidad propia de la luz, la segunda tiene lugar entre tinieblas. Este hecho para el Niseno no reviste contradicción sino progreso. En la zarza ardiendo, Moisés aprendió como propio de la luz que sólo Dios es el que es, que sólo Él es lo verdaderamente existente. En esta segunda teofanía que tiene como lugar el monte Sinaí, Moisés aprende algo superior: que el conocimiento de la naturaleza divina es inalcanzable a la inteligencia humana, por esta razón, en este lugar se llama luminosa a la tiniebla, pues se trata de un ver sin ver. Si bien, para Gregorio la esencia de Dios es inaccesible, no pasa lo mismo con su existencia que se ha manifestado por su acción en el mundo, según Daniélou (1941: 83)

Pues la armonía de las maravillas existentes en el cielo canta la sabiduría divina que resplandece en el universo y proclama por medio de las cosas visibles la gran gloria de Dios, conforme a lo que está dicho: 'los cielos proclaman la gloria de Dios'. 
En clave de paideia es posible señalar la correlación directa que existe entre conocimiento de Dios y vida virtuosa como las dos caras de la misma moneda, como los elementos con los cuales se realiza la virtud a la cual Gregorio relaciona con la vida cristiana. Más aún, a quien está dedicado al progreso en la virtud le asiste una ayuda dada por Dios a nuestra naturaleza que es anterior a nosotros, pero que se da a conocer siempre que decidimos a consciencia en función del bien.

Si en la primera teofanía Moisés aprendió que conocer a Dios consiste en no formarnos ninguna idea de Él a partir de las cosas conocidas según la forma humana de conocer, cree ahora en Dios y comprende con qué modo de vivir se conduce rectamente la vida virtuosa. Por esta razón, se presenta la subida del espíritu a través de la escala de los seres, simbolizada en la subida a la montaña del conocimiento (Teología) que conlleva el apartamiento de las realidades sensibles y el irse acostumbrando a las realidades invisibles.

Por último, la tercera teofanía que aborda el De vita Moysis, que tiene lugar en la hendidura de la roca es tratada con mayor detenimiento y constituye el punto culminante de la obra. A pesar de que Moisés ya ha hablado con Dios cara a cara, como quien habla con un amigo (Ex 33, 11), insiste en verle. Al respecto, la razón del Niseno remite a que la naturaleza del Bien atrae hacia sí a quienes la miran (Daniélou, 1941:112114).

En la medida en que el hombre, liberándose de la mentira, contempla el Bien, en esa medida siente surgir en su corazón la atracción del Bien. Y mientras más lo alcanza, más lo desea, pues, al conocerle mejor, siente su atracción con más fuerza (Daniélou, 1941). Para Gregorio, el deseo de Dios lleva consigo la gozosa paradoja de que la satisfacción del deseo agranda la capacidad para un nuevo deseo, porque quien busca la virtud y, por tanto a Dios nunca para en el deseo de la búsqueda (Daniélou, 1941).

Es la práctica de la virtud que implica seguir a Dios, aquello que diviniza al hombre, divinización que permite a cada hombre ver a Dios de la manera cómo es posible, según Daniélou, (1941: 107): «seguir a Dios a donde conduce, eso es ver a Dios». Para el hombre hacerse semejante a Dios significa ir purificándose en la lucha contra el pecado y las pasiones e ir adquiriendo virtudes. De este modo, todos pueden contemplar a Dios en sí mismos como un anticipo y una participación de la visión beatífica. Para Gregorio, en cuanto más sólida y firmemente se mantiene uno en el bien, tanto más se consuma la carrera de la virtud y su correlativo, el conocimiento de Dios. Según Daniélou (1944: 47), «Este es un mismo movimiento que atraviesa todos los textos: conocimiento de sí 
por purificación de todo aquello que es exterior y conocimiento de Dios en sí̀.

En clave de paideia es posible señalar que la enseñanza de esta tercera teofanía se concreta en una exhortación al seguimiento de Dios y de Cristo. La esencia de la paideia cristiana es el seguimiento de Dios, es decir, el seguimiento de Cristo, quien es la virtud perfecta. Sólo así es posible vivir como amigo de Dios y ser reconocido como su servidor.

\section{Conclusión}

Comprender la Escritura como la paideia cristiana por excelencia, exige que el teólogo no sólo debe destacarse por el conocimiento científico que pueda hacerse de ella, sino por la constante meditación de la misma, que no sólo lo capacita para avanzar en la búsqueda de un bien mayor y avanzar en el conocimiento de Dios, sino también para poder dirigirse y guiar a otros.

En el caso particular de Gregorio de Nisa, el testimonio de vida fue esencial en la manera como hizo posible la apropiación de la noción de paideia $y$, por ende, la inculturación de la teología. Fue una teología realizada en referencia a la santidad de vida, pero santidad entendida como la búsqueda permanente de un bien mayor, pues esa es la perfección a la cual puede aspirar el hombre para vivir como amigo de Dios y ser reconocido como su servidor.

Para terminar, considero oportuno citar una frase de Zubiri (1925: 219) a propósito de la referencia a personajes que han dejado un legado a la humanidad: «Los hombres geniales lo son más que por los productos que nos legan, por el espíritu que nos trasmiten, en cuya secreta fecundidad hay siempre recursos para abordar nuevas cuestiones».

Esta frase de Zubiri es importante, particularmente en este nivel de la reflexión, pues lo que se busca al evocar la tradición de los Padres de la Iglesia, es recoger el espíritu presente en ellos, en sus obras, sin otra pretensión diferente a enriquecer el quehacer teológico en estos inicios de siglo y de milenio con el legado de aquellos genios que nos han antecedido, como es el caso del obispo de Nisa.

\section{REFERENCIAS}

-Aguilar, F. S. (2010). Evangelizar. Madrid: Ediciones Encuentro.

-Balderas, G. (2007). Jesús, cristianismo y cultura en la Antigüedady en la Edad Media. México: Universidad Iberoamericana.

-Daniélou, J. (1941). Grégoire de Nysse. Contemplation sur la vie de Moise ou Traité de la perfection en matiére de vertu. Paris: Du Cerf. 
-Daniélou, J. (1944). Platonisme et théologie mystique, essai sur la doctrine spirituelle de saint Grégoire de Nysse. París: Aubier.

-Daniélou, J. (1976). Grégoire de Nysse et la Philosophie. En H. Dörrie, M. Altenburger \& U. Schramm (Eds.), Gregor von Nyssa und die Philosophie. Zweites Internationales Kolloquium über Gregor von Nyssa: Leiden.

-Escalante, L. A. (2010). Teología fundamental en tiempos de globalización. Revista Iberoamericana de Teología, VI (11), 55-103.

-Estermann, J. (2008). Si el Sur fuera el Norte. Chakanas interculturales entre Andes y Occidente. Quito: Abya-Yala.

-Ferrer, E. (2006). Preposiciones y esquemas simbólicos en 'De Vita Moysis’ de Gregorio de Nisa. Revista de Estudios Clásicos (33) 33-51.

-García Gilbert, J. (2010). Sobre el viejo humanismo: exposición y defensa de una tradición. Madrid: Marcial Pons, Ediciones de la Historia.

-Garrard-Burnett, V. (2004). Inculturación de la Teología protestante en Guatemala. En M. H. Ruz \& G. Garma Navarro (Eds.), Protestantismo en el mundo contemporáneo (págs. 49-64). México: UNAM.

-González, R. (2002-2003). Autores griegos cristianos y "anábasis" órfica. Archivum, 52-53: 197-224.

-Jaeger, W. (2001). Paideia: los ideales de la cultura Griega (Vol. Ia-IIb-IIIc) México: FCE.

-Jaeger, W. \& Frost, E. C. (1974). Cristianismo Primitivo y Paideia Griega (Breviarios del FCE. Vol. 182) México: FCE.

-Orlandis, J. (1999). Historia breve del cristianismo. Madrid: Rialp.

-Ramos, G. D. (2011). Hacer teología de otra manera. No 2373. Agosto. En http://www.revistacriterio.com.ar/cultura/hacer-teologia-de-otra-manera/ (Consultado el 9 de julio de 2013).

-Ruiz, J. I. (2007). El concepto de verdad en Gregorio de Nisa. ScrTh Vol. 39 (1), 13-35.

-Susin, L. C. (1995). Teologia da inculturação e inculturação da teologia. En M. Fabri Dos Anjos, Teologia da inculturação e inculturação da teologia, Petrópolis: Vozes/Soter.

-Trevijano, R. (1994). Patrología. Madrid: BAC.

-Uribarri, G. (2007). Contexto y Nueva Evangelización. Madrid: Universidad de Comillas.

-Verteuil, M. (1994). Trasfondo teológico de la inculturación: la Lectio Divina. Selecciones de Teología, 33 (129), 33-44.

-Zubiri, X. (1925). La crisis de la conciencia moderna. La Ciudad de Dios (141), 202-221.

Sumario: Introducción; 1. Noción de Paideia; 2. Uso de la noción de paideia por Gregorio de Nisa; 3. La paideia cristiana y el De Vita Moysis; Conclusión; Referencias. 